\title{
Comparative Analysis of Program Outcomes Achievement between Face-to-Face and Virtual Classes during COVID-19 Pandemic
}

\author{
M Tanseer Ali, Md. Abdur Rahman and Carmen Z. Lamagna
}

\begin{abstract}
Outcome-based education is a paradigm shift from traditional knowledge-based education to modern skill-based education. After the Washington Accord, engineering education worldwide has adopted the new pedagogy for Engineering Education. But last year, after the hit of COVID - 19 pandemics, most of the education system has to move online. The online education platform raised a new challenge for Outcome-Based Education. In this paper, online education on the OBEimplemented B.Sc. in Electrical and Electronic Engineering (EEE) program has been analyzed. The attainment performance of the Program Outcomes has been presented. With this empirical evidence, careful implementation and encouragement of $O B E$ can achieve its potential even with Online education. Students and Faculties of the B.Sc in EEE program have demonstrated that OBE can be effectively accomplished via an e-learning platform.
\end{abstract}

Index Terms - Outcome Based Education, Engineering Education, E-learning.

\section{INTRODUCTION}

$\mathrm{D}$ URING the COVID-19 pandemic closure, the universities worldwide have been faced a new challenge to deliver continuing education to students without putting students and teachers at health and safety risks. The education institutes were closed, and students had to stay at home for the closure. Bangladesh government has closed down all the educational institutes from March 18, 2020.[1] Till now, in March 2020, all the educational institutes and physical campuses are officially closed. As a situation instilled with uncertainty for current students enrolled for an undergraduate degree, there was no

M Tanseer Ali

Senior Assistant Professor,

Department of Electrical and Electronics Engineering

American International University - Bangladesh

Email: tanseer@aiub.edu

Md. Abdur Rahman

Professor and Associate Dean, Faculty of Engineering

American International University - Bangladesh

Email: arahman@aiub.edu

Carmen Z. Lamagna

Vice Chancellor,

American International University - Bangladesh

Email: clamagna@aiub.edu alternative but to consider e-learning platforms and continue teaching-learning activities. American International University - Bangladesh was the first university to move online using Microsoft Teams completely. [2]

The Electrical and Electronics Department has played a leading role in implementing outcome-based education for the international and local accreditation to achieve the requirements of Washing Accord Engineering Education.[3,4] From Spring 17-18 semester, the outcome-based education was fully implemented for the B.Sc. in Electrical and Electronics Engineering. The program also got accreditation from the Board of Accreditation for Engineering and Technical Education (BAETE) in March 2019.

While Outcome-Based Education is yet to be recognized by students and teachers, another challenge comes as an e-learning platform. E-learning platform opens up a vast opportunity to explore, provides more flexibility for both teachers and students, and is enhanced with resources. Since outcome-based education primarily focuses on skill-based teaching and learning, most of the Program Outcomes (PO) for the BSc in EEE program at AIUB were attained through lab-based activities. Hence shifting to entirely online to achieve the specific course outcome was challenging.

During the initial closure of AIUB, the Faculty of Engineering Management and faculties have decided to continue with the planned activities and assessment process for Spring 19-20. Later for the Summer 19-20 semester, some modifications were made through Continuous Quality Assurance (CQI) meeting and adopted some methods to assess the course objectives (COs) to attain the Program Outcome (POs).

In this paper, the data for achievement of COs and POs were presented for one academic year 19-20, where Fall 19-20 was face-to-face teaching, Spring 19-20 was partially online, and Summer 19-20 entirely online. Comparison and analysis will provide insight into the attainment of POs and the effectiveness of e-learning to face-to-face teaching. 


\section{OUTCOME-BASED ENGINEERING EDUCATION}

The outcome-based approach in engineering education has been assigned as compulsory for accrediting the engineering programs for signatories of the Washington Accord. The Washington Accord provides the guideline of the graduate attributes to ensure accreditation to tertiary education programs that qualify graduates for entry to professional engineering practice. [3] The current BSc curriculum in EEE at AIUB is equipped with the Outcome-based (OBE) teaching-learning process, which has been implemented from January 2018 for Spring 17-18 Semester.

Outcome-based engineering education has three main components, Program Outcome (PO), Program Outcome Indicator (POI), and Course Outcome. According to the BAETE accreditation manual, the 12 POs are made compulsory to be attained by the BSc program. [5]

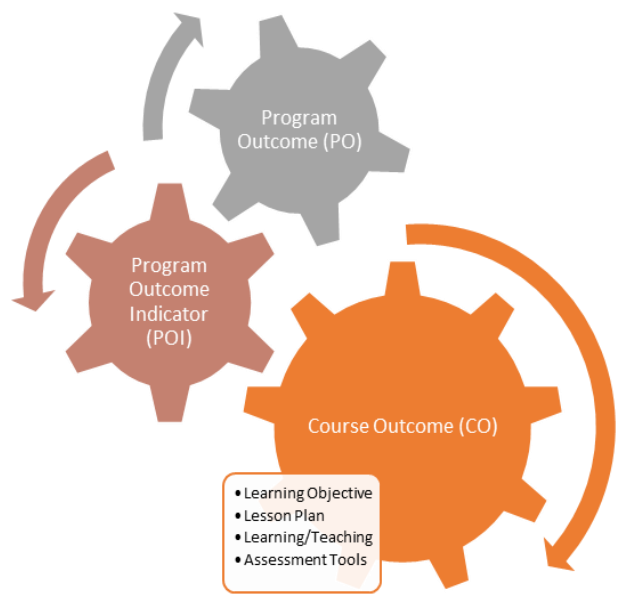

Fig. 1. OBE Components

The 12 POs are defined as follows:

PO-a. Apply knowledge of mathematics, natural science, engineering fundamentals and an engineering specialization as specified in $\mathrm{K} 1$ to $\mathrm{K} 4$ respectively to the solution of complex engineering problems.

PO-b. Identify, formulate, research literature and analyse complex engineering problems reaching substantiated conclusions using first principles of mathematics, natural sciences and engineering sciences. (K1 to K4).

PO-c. Design solutions for complex engineering problems and design systems, components or processes that meet specified needs with appropriate consideration for public health and safety, cultural, societal, and environmental considerations. (K5).

PO-d.Conduct investigations of complex problems using research-based Knowledge (K8) and research methods including design of experiments, analysis and interpretation of data, and synthesis of information to provide valid conclusions.

PO-e. Create, select and apply appropriate techniques, resources, and modern engineering and IT tools, including prediction and modelling, to complex engineering problems, with an understanding of the limitations. (K6).

PO-f. Apply reasoning informed by the contextual knowledge to assess societal, health, safety, legal and cultural issues and the consequent responsibilities relevant to professional engineering practice and solutions to complex engineering problems. (K7)

PO-g. Understand and evaluate the sustainability and impact of professional engineering work in the solution of complex engineering problems in societal and environmental contexts. (K7)

PO-h. Apply ethical principles and commit to professional ethics and responsibilities and norms of engineering practice. (K7)

PO-i. Function effectively as an individual and as a member or leader in diverse teams and in multidisciplinary settings.

PO-j. Communicate effectively on complex engineering activities with the engineering community and with society at large, such as being able to comprehend and write effective reports and design documentation, make effective presentations, and give and receive clear instructions.

PO-k. Demonstrate knowledge and understanding of engineering management principles and economic decision-making and apply these to one's own work as a member and leader in a team to manage projects and in multidisciplinary environments.

PO-1. Recognize the need for and have the preparation and ability to engage in independent and life-long learning in the broadest context of technological change.

Multiple COs of different core courses effectively attains these POs. Initially, achieving a single PO with a single $\mathrm{CO}$ was difficult and loaded; some of the requirements were misaligned. Therefore, from Fall 19-20, a new OBE structure was developed and implemented. In this new system, each POs were subdivided into more achievable components considered as Program Outcome Indicators (POIs). These POIs were then assigned to different courses, and then a single $\mathrm{CO}$ was aligned to attain single POI. The achievement of POs was then accumulated from the accomplishment of POIs through multiple COs. This method was proven much effective and achievable by students and faculties. For example, the first POa was subdivided into four POIs, as shown in the following table:

TABLE I: POI OF PO-A

\begin{tabular}{|c|c|c|c|c|}
\hline POs & POI Code & POI Statement & $K$ & $P$ \\
\hline \multirow[t]{4}{*}{$\begin{array}{r}a . \\
\text { Engineering } \\
\text { Knowledge }\end{array}$} & P.a.1.C3 & $\begin{array}{l}\text { Apply information and } \\
\text { concepts in natural science } \\
\text { with the familiarity of } \\
\text { issues. }\end{array}$ & K1 & \\
\hline & P.a.2.C3 & $\begin{array}{l}\text { Apply information and } \\
\text { concepts of mathematics } \\
\text { with the familiarity of } \\
\text { issues. }\end{array}$ & $\mathrm{K} 2$ & \\
\hline & P.a.3.C3 & $\begin{array}{l}\text { Apply information and } \\
\text { concepts in engineering } \\
\text { fundamentals to solve } \\
\text { complex engineering } \\
\text { problems with a range of } \\
\text { conflicting requirements. }\end{array}$ & K3 & $\begin{array}{l}\text { P1, } \\
\text { P2, } \\
\text { P6 }\end{array}$ \\
\hline & P.a.4.C3 & $\begin{array}{l}\text { Apply information and } \\
\text { concepts in specialized } \\
\text { engineering sciences with } \\
\text { the in-depth analysis of a } \\
\text { complex engineering } \\
\text { problem. }\end{array}$ & K4 & $\begin{array}{l}\text { P1, } \\
\text { P3, } \\
\text { P7 }\end{array}$ \\
\hline
\end{tabular}


Each of the POI has also been mapped with Knowledge Profile (K), Complex Engineering Problem (P), and Complex Engineering Activity (A). Hence assessment and attainment become more specific and achievable. A unique code structure was followed to identify the Program Outcome Indicator (POI), the PO, the number of the subpart, and then the domain. For example, P.a.1.C3 refers to PO-a's first subpart, which is recognized at cognitive domain 3 .

In this paper, the assessment results of the COs, which are mapped with specific POIs, are highlighted to understand the achievement efficiency of the OBE implemented. The complete OBE structure and teaching-learning process are beyond the scope of this paper.

\section{ASSESSMENT OF COURSE OUTCOMES}

The 12 POs were attained through 38 different courses, which are mapped with 35 POIs. Each POIs were also mapped with two different courses so that if one student misses the requirements of one POI from one course, he has the opportunity to achieve it through another course. Three assessment tools have been presented here, separating them through KPA mapping to explain the assessment process.

\section{A. CO Assessment with Knowledge Profile:}

First, the COs mapped with Knowledge profile criteria is presented in this section. For example "Electrical Circuits 1 (DC)" course can be considered, where PO-a has been mapped through P.a.1.C3 POI and mapped with K1. From the CO statement, it is apparent that the students are required to apply the theory-based understanding of natural science, in this case, the concepts in basic electrical properties and atomic structure of materials, the flow of charge, effects of temperature onresistance of material, etc. Therefore, the course teachers and course coordinator have developed an in-class quiz question for assessing cognitive domain level 3. The assessment tool for the Fall 19-20 semester was as following:

\section{Course Title: Electrical Circuits 1 (DC) \\ KPA Mapping: K1: A systematic, theory-based} understanding of the natural sciences applicable to the discipline.

CO Statement: Apply information and concepts in basic electrical properties and atomic structure of materials, flow of charge, effects of temperature on resistance of a material, etc. with the familiarity of issues to calculate different electrical parameters in circuits containing DC source.

Method(s): Out of five COs, CO1 has been assessed for OBE attainment. In mid-term, quiz 1 has been taken for the assessment of CO1. The quiz question was based on the topics covered on week 1 and 2 of the course outline.

Tool(s): The quiz questions were given as follows:

1. (i) Aluminum material with cross sectional area of $3 \times 10^{-9}$ $\mathrm{m}^{2}$ and length of $0.63 \mathrm{~cm}$ poses a resistivity of $2.825 \times 10^{-6} \Omega \mathrm{m}$ at $20^{\circ} \mathrm{C}$. Compute the value of the resistance. Infrared Absolute Temperature for Aluminum is $-236^{\circ} \mathrm{C}$. [Marks: 2]

(ii) What would happen to the resistance if the temperature increased to $100^{\circ} \mathrm{C}$ ? Express your answer with proper calculation. [Marks: 2]

2. (i) Calculate the power P1 and P2 dissipated by each resistor of Figure 2. [Marks: 2]

(ii) Calculate the number of electrons associated with these powers if the currents flow through resistor for 15 minutes. [Marks: 4]

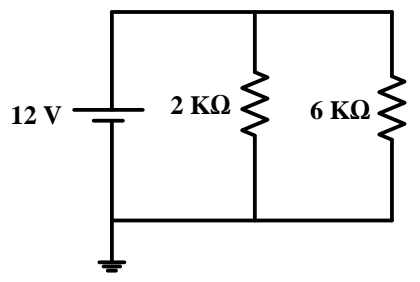

The figure for Question 2

3. An oven connected to a $12 \mathrm{~V} \mathrm{DC}$ source consists of two elements having resistances of $0.6 \Omega$ and $0.8 \Omega$. The elements provide low heat when connected in series and high heat when connected in parallel. Calculate the power delivered by the 12 V DC source at (i) low and (ii) high heat settings. [Marks: 4]

4. An electric stove with two burners and two ovens is used in preparing dinner as follows:

Burner $1 \quad 120 \mathrm{~W} \quad 20$ minutes

Burner $2120 \mathrm{~W} \quad 15$ minutes

Oven $1 \quad 180 \mathrm{~W} \quad 45$ minutes

Oven $2160 \mathrm{~W} \quad 20$ minutes

(i) If electricity costs $10 \mathrm{BDT}$ per $\mathrm{kWh}$, calculate the cost of electricity used in preparing the dinner. [Marks: 4]

(ii) If burner 2 and oven 1 are turned on for $4 \mathrm{~h}$ with nobody using it, then calculate how much money is wasted? [Marks: 2]

According to $\mathrm{CO}$ requirement, for the answering the question no. 1 and 2 , the student must understand the effect of temperature on resistance of different materials and apply their knowledge to relate the basic parameters of electrical circuits, i.e., the flow of charge, power, etc.

Question no. 3 and 4 have been mapped to K1, where the theories behind series-parallel networks, their heating effects, and the cost calculation has been involved.

\section{B. CO Assessment with a Complex Engineering Problem:}

The example course has been considered "Microprocessor and Embedded Systems" to provide an example of Complex Engineering Problem assessment, which was mapped with POd through P.d.1.P3 POI mapped with P1, P2, and P6 along with knowledge profile K8. The evaluation was carried out through Group projects as the domain of the requirements was suitable for Psychomotor Level 3 (Precision).

Course Title: Microprocessor and Embedded Systems

KPA Mapping: K8: Engagement with selected knowledge in the research literature of the discipline. P1: Depth of knowledge required: Cannot be resolved without in-depth engineering knowledge at the level of one or more of K3, K4, K5, K6 or K8 which allows a fundamentals-based, first principles analytical approach. P2: Range of conflicting requirements: Involve wide- 
ranging or conflicting technical, engineering, and other issues. P6: Extent of stakeholder involvement and conflicting requirements: Involve diverse groups of stakeholders with widely varying needs.

CO Statement: Design Experiment to test complex engineering problems for certain constraints through appropriate research.

Method(s): In final term, a microcontroller-based engineering project has been given to students. The project is group-wise, and a project report and demonstration by the students are assessed to attain the CO.

Criteria: The students are asked to analyze some societyrelated issues and do a survey. A project including the report will be accessed for the student's knowledge focusing on novelty, test-bench embedded system design followed by data analysis and impact on society and environment also. The projects designed and implemented by different groups are as follows:

1. Development of devices for controlling mosquito breeding and mosquito larvae killer using ultrasonic sound

2. Solar tracking using Arduino

3. Smart vehicle parking system using IOT

4. Smart rat trap using Arduino Uno

According to $\mathrm{CO}$ requirement, for doing the project, where the students must design experiments to test complex engineering problems for certain constraints through appropriate research, which also fulfills the requirement of Knowledge Profile KP8. The second part of the project report has been mapped to Complex Problem P1, P2, and P6. Since the project required to do some research on Microcontroller programming to complete the project, it meets K8 and P1. Each of the selected projects has sub-parts to be resolved with varying out the range of solutions; hence it meets the requirements of P2. Finally, as P6 requirement, the stakeholder's relation is considered the given projects to be solved by considering social and environmental needs.

\section{CO Assessment with Complex Engineering Activities:}

The assessment of the course "Engineering Ethics" has been presented here as the example assessment of the COs with Complex Engineering Activities. The specific $\mathrm{CO}$ of the course has been mapped with PO-j through P.j.2.P3 POI along with A1 and $\mathrm{A} 5$. In addition to that, the $\mathrm{CO}$ has been identified as equivalent to Psychomotor Level 3 (Precision). Hence the assessment tool utilized for Fall 19-20 semester has been presented as follows.

Course Title: Computer Aided Design \& Drafting

KPA Mapping: A1: Range of resources: Involve the use of diverse resources (and for this purpose, resources include people, money, equipment, materials, information, and technologies). A5: Familiarity: Can extend beyond previous experiences by applying principles-based approaches.

CO Statement: Produces written engineering reports by applying principle-based approaches and design documentation on complex engineering activities for different stakeholders.

Method(s): In the Final term, an in-class assignment for CO5 assessment has been given to students. The assignment was based on preparing documentation on code-of-conduct for AIUB EEE graduates.

Tool(s): Students are to exploit diverse resources (class lectures, notes, case studies, code-of-ethics, research papers etc.) and utilize their understanding from the course, prepare documentation on code-of-conduct for AIUB EEE graduates focusing on:

a) Comprehension of the role of engineers in society

b) Engineering responsibility to public safety.

As per the description of $\mathrm{CO}$, students require to demonstrate A1: Involve the use of diverse resources (and for this purpose, resources include people, money, equipment, materials, information, and technologies) and A5: Can extend beyond previous experiences by applying principles-based approaches. Students need to utilize the diverse resources (class lectures, notes, case studies, code-of-ethics, research papers etc.) and their understanding from the course; hence it meets the requirements of $\mathrm{A} 1$. While writing the code of conduct in the report form, students have to demonstrate Innovative thinking based on other codes of ethics discussed in the class; hence it also satisfies the A5 requirements.

\section{ATtAINMENT OF PROGRAM OUTCOMES}

The attainment analysis of POs has been done in reverse compared to $\mathrm{PO}$ - CO mapping. The complete process of PO attainment can be summarized in Figure 2.

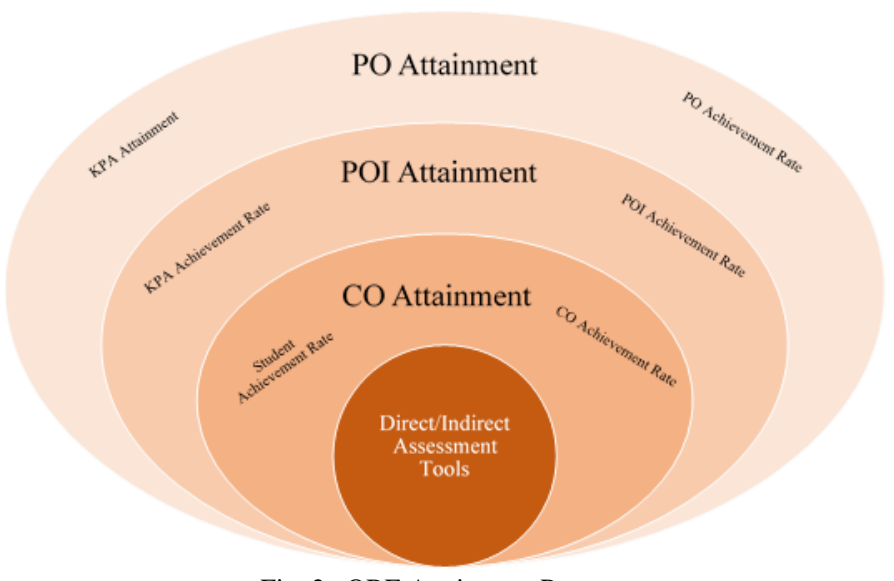

Fig. 2. OBE Attainment Process

The achievement rate measures the attainment of COs after the evaluation through various $\mathrm{CO}$ assessment tools described in section 8.4. The scale has been considered $60 \%$ for the assessment process, i.e., students secure more than $60 \%$ marks from the $\mathrm{CO}$ assessment process, then they are deemed to have met the requirements of COs. The achievement rate of each $\mathrm{CO}$ has been calculated using the following equation (1). 
Achievement Rate of $\mathrm{CO}$

number of students who attained the CO (scored above 60\%) total number of students in the class $100 \%$

For each section of the courses, if the achievement rate is found to more than $60 \%$, CO for that section of the course has been achieved. Following that, excel files of the assessed COs for each semester are collected from course teachers along with an OBE report explaining the assessment process and indicating the achievement rates. These data are kept in a SQL database. And from there, combined $\mathrm{CO}$ achievement rates for all the sections of the course are calculated. A semester-wise OBE report is prepared by the $\mathrm{OBE}$ committee and presented to the department head. If the overall achievement rate of all the sections of a specific course has reached over $60 \%$, then the $\mathrm{CO}$ attainment in the course level is considered to be achieved.

Since all the courses are mapped with at least one POI, the POI level attainment is assessed through the achievement rate of the mapped CO. POIs and mapped with KPA; hence there is load variance of different POIs of the same PO. Therefore to analyze the PO's attainment, each POIs have been considered with a weight according to their burden with KPA requirements. Utilizing the POI achievement level and weight, the overall PO attainments are calculated by the following formula.

Achievement Rate of $\mathrm{CO}=$ Achievement Rate of POI ... (2)

Achievement Rate of $\mathrm{PO}$

$=$ weight of the POI $\times$ Achievement Rate of POI

When the PO achievement rate has reached over $60 \%$, then the specific $\mathrm{PO}$ is considered to be attained employing commutative achievement of POIs and COs. If the PO's requirements have not been met and the $\mathrm{PO}$ is not acquired, then the $\mathrm{OBE}$ assessment process gap can be traced back to $\mathrm{CO}$ and the course from the database, and the OBE committee will recommend the CQI update of the specific course. Since OBE has been implemented in the EEE program at AIUB from Fall 18-19 semester, there was much to learn and understand outcome-based education. Hence, the management, OBE committee, and course teachers decided that the OBE structure should be implemented across all the EEE curriculum for all the existing EEE students. This seamless implementation would provide us insights into the OBE assessment and attainment process to be more effective.

Student level attainment of OBE and PO attainment will be given to students during graduation as OBE certificate, indicating which of the 12 POs has been attained. Although student batches before Fall 18-19 will not be getting full OBE reports. EEE students from Fall 18-19 onwards will receive the complete OBE certificate. PO attainments are accomplished by aggregated $\mathrm{CO}$ achievement of the mapped POI; hence students may achieve a particular PO through multiple semesters by different courses. Therefore, unless an entire four-year EEE program has been completed by a batch, the student level PO attainment cannot be calculated. For example, PO-a is assessed and evaluated with the help of four POI, namely P.a.1.C3, P.a.2.C3, P.a.3.C3 and P.a.4.C3. These POIs are mapped with 8 different courses. According to the semester wise flow chart, Electrical Circuits - 1 (DC) should be completed in Semester 2, Electrical Circuits - 2 (AC) in Semester 3, Electronic Devices and Electrical Machines - 1 in semester 4, Electrical Properties of Material, Analog Electronics and Signal and Linear System in semester 5, Industrial Electronics and Drives in semester 7. So, in order to get full attainment of PO-a, students have to complete these eight courses that can take up to semester 7, and then the overall attainment of PO-a in student level. The integrated database and reporting similar to grading system are under development which will be able provide this student level PO attainment analysis. Since the updated POI system OBE is being practiced only from Fall 19-20 semester, we are still unable to get the student level attainment analysis.

The following example data for the PO-a and PO-b attainment analysis is presented on Semester wise CO, POI and PO achievement rate. This data helps to analyze the effectiveness of overall OBE implementation.

\section{A. Attainment of $\mathrm{PO}(a)$ : Engineering Knowledge:}

$\mathrm{PO}$ (a) is assessed and evaluated with the help of four POI, namely P.a.1.C3, P.a.2.C3, P.a.3.C3 and P.a.4.C3. These POIs are mapped with 8 different courses: Electrical Circuits - 1 (DC), Electrical Properties of Material, Electrical Circuits - 2 (AC), Signal and Linear System, Electrical Machines - 1, Electronic Devices, Industrial Electronics and Drives, and Analog Electronics. The methods, tools, criteria, and scale used in the assessment process are described in section 8.4. The expected level of attainment has been $60 \%$ or above. Knowledge Profile attributes K1, K2, K3, and K4 are incorporated in $\mathrm{PO}(\mathrm{a})$. The attributes of the Complex Engineering Problems, P1, P2, P3, P6, and P7, are addressed through the attainment of $\mathrm{PO}(\mathrm{a})$. The weight of the POIs was given according to the KPA mapping, P.a.1.C3 and P.a.2.C3 each was given $20 \%$ weights to calculate total PO(a), whereas P.a.3.C3 and P.a.4.C3 each were given 30\% weights as these POIs had more load with KPA requirements.

A summary of the results (Table II and Figure 3) obtained after the assessment of Academic Year 19-20 (Three semesters) to demonstrate the $\mathrm{PO}(\mathrm{a})$ is being attained.

TABLE II: ATTAINMENT OF PO(A) FOR ACADEMIC YEAR 19-20

\begin{tabular}{|c|c|c|c|c|c|}
\hline \multirow[t]{2}{*}{ POI/PO } & \multirow[t]{2}{*}{ WEIGHT } & \multirow[t]{2}{*}{ KPA } & \multicolumn{3}{|c|}{ ACHIEVEMENT RATES } \\
\hline & & & $\begin{array}{c}\text { Fall } 19 \\
-20\end{array}$ & $\begin{array}{c}\text { Spring } \\
19-20\end{array}$ & $\begin{array}{c}\text { Summer } \\
19-20\end{array}$ \\
\hline P.a.1.c3 & 0.2 & K1 & $70.83 \%$ & $87.95 \%$ & $95.92 \%$ \\
\hline P.a.2.c3 & 0.2 & K2 & $76.79 \%$ & $88.65 \%$ & $89.88 \%$ \\
\hline P.a.3.c3 & 0.3 & $\begin{array}{l}\text { K3, P1, } \\
\text { P2, P6 }\end{array}$ & $87.68 \%$ & $85.49 \%$ & $87.00 \%$ \\
\hline P.a.4.c3 & 0.3 & $\begin{array}{l}\text { K4, P1, } \\
\text { P3, P7 }\end{array}$ & $91.57 \%$ & $90.00 \%$ & $95.19 \%$ \\
\hline $\begin{array}{c}\text { Overall } \\
\text { PO-a }\end{array}$ & 1 & $\begin{array}{c}\mathrm{K} 1, \mathrm{~K} 2, \\
\mathrm{~K} 3, \mathrm{~K} 4, \\
\mathrm{P} 1, \mathrm{P} 2, \mathrm{P} 3, \\
\mathrm{P} 6, \mathrm{P} 7\end{array}$ & $83.30 \%$ & $87.97 \%$ & $91.82 \%$ \\
\hline
\end{tabular}




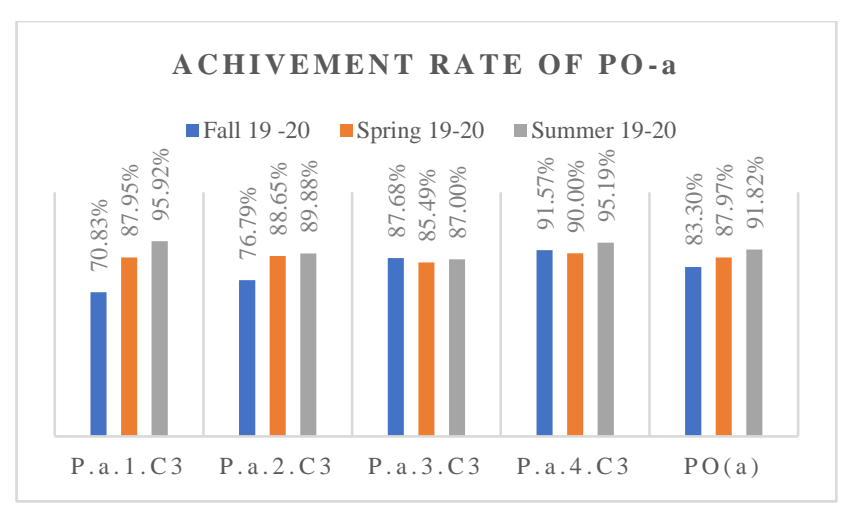

Fig. 3. Attainment of PO-a for Academic Year 19-20

From the results, it is apparent that collectively through POIs, the PO(a) has been achieved by $83.30 \%$ in Fall 19-20, 87.97\% in Spring 19-20, and 91.82\% in Summer 19-20.

\section{B. Attainment of $P O(b)$ : Problem Analysis}

$\mathrm{PO}(\mathrm{b})$ is assessed and evaluated with the help of four POI, namely P.b.1.C4, P.b.2.C4, P.b.3.C4 and P.b.4.C5. These POIs are mapped with eight different courses: Electromagnetic Fields and Waves, Modern Control System, Digital Signal Processing, Digital Logic Circuits, Power System Analysis, Electrical Machines - 2, Capstone Project, and Telecommunications Engineering. The methods, tools, criteria, and scale used in the assessment process are described in section 8.4. The expected level of attainment has been $60 \%$ or above.

$\mathrm{K} 1, \mathrm{~K} 2, \mathrm{~K} 3$, and $\mathrm{K} 4$ among Knowledge Profile attributes are incorporated in $\mathrm{PO}(\mathrm{b})$. P1, P2, P4, P5, and P6 of the attributes of the Range of Complex Engineering Problems are addressed through the attainment of PO - b. The weight of the POIs was given according to the KPA mapping. P.b.1.C4 and P.b.2.C3 each were given $20 \%$ weights to calculate total $\mathrm{PO}(\mathrm{b})$, whereas P.b.3.C4 and P.b.4.C3 were given 30\% weights as these POIs had more load with KPA requirements.

A summary of the results (Table III and Figure 4) obtained after the assessment of Academic Year 19-20 (Three semesters) to demonstrate the $\mathrm{PO}(\mathrm{b})$ is being attained.

TABLE III: ATTAINMENT OF PO(B) FOR ACADEMIC YEAR 19-20

\begin{tabular}{|c|c|c|c|c|c|}
\hline \multirow[t]{2}{*}{ Poi/Po } & \multirow[t]{2}{*}{ Weight } & \multirow[t]{2}{*}{ Кра } & \multicolumn{3}{|c|}{ Achievement Rates } \\
\hline & & & $\begin{array}{l}\text { Fall } 19 \text { - } \\
20\end{array}$ & $\begin{array}{c}\text { Spring } \\
19-20\end{array}$ & $\begin{array}{c}\text { Summer } \\
19-20\end{array}$ \\
\hline P.b.1.c4 & 0.2 & K1 & $82.16 \%$ & $91.28 \%$ & $84.65 \%$ \\
\hline P.b.2.c3 & 0.2 & K2 & $76.60 \%$ & $94.38 \%$ & $93.01 \%$ \\
\hline P.b.2.c4 & 0.3 & $\begin{array}{c}\mathrm{K} 3, \mathrm{P} 1, \mathrm{P} 2, \\
\text { P6 }\end{array}$ & $84.60 \%$ & $83.44 \%$ & $82.09 \%$ \\
\hline P.b.4.c3 & 0.3 & $\begin{array}{c}\mathrm{K} 4, \mathrm{P} 1, \mathrm{P} 3, \\
\text { P7 }\end{array}$ & $76.56 \%$ & $93.18 \%$ & $89.94 \%$ \\
\hline $\begin{array}{c}\text { Overall } \\
\text { PO-b }\end{array}$ & 1 & $\begin{array}{c}\mathrm{K} 1, \mathrm{~K} 2, \mathrm{~K} 3, \\
\mathrm{~K} 4, \mathrm{P} 1, \mathrm{P} 2, \\
\mathrm{P} 4, \mathrm{P} 5, \mathrm{P} 6\end{array}$ & $80.10 \%$ & $90.12 \%$ & $87.14 \%$ \\
\hline
\end{tabular}

\section{ACHIVEMENT RATE OF PO-b}

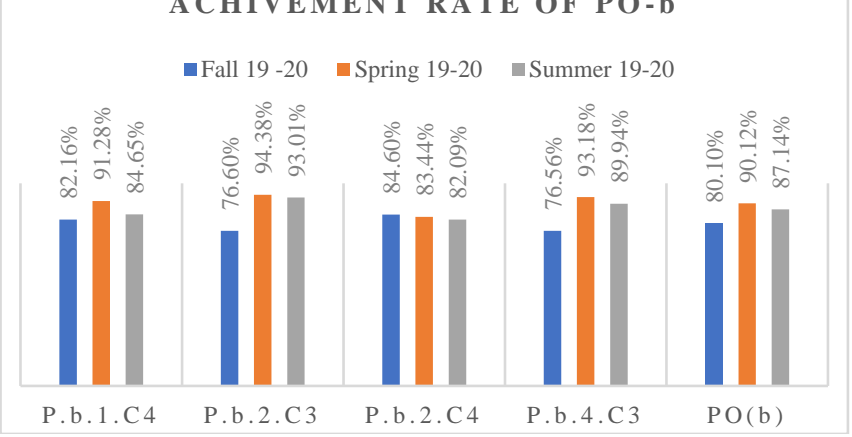

Fig. 4. Attainment of PO-b for Academic Year 19-20

From the results, it is apparent that collectively through POIs, the $\mathrm{PO}(\mathrm{b})$ has been achieved by $80.10 \%$ in Fall $19-20,90.12 \%$ in Spring 19-20, and 87.14\% in Summer 19-20.

\section{COMPARATIVE ANALYSIS}

All the data collected from the $12 \mathrm{PO}$ attainment over an academic year, the achievement rates can be summarized in the following graph.

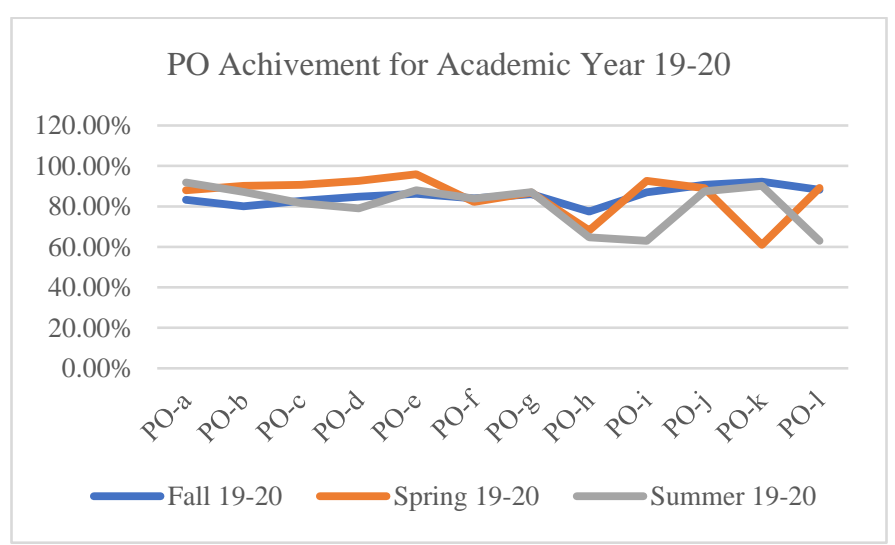

From the above curve, it can be observed that the Fall 19-20 semester's PO achievement rates were more stable, averaging an $85.28 \%$ achievement rate. For Spring 19-20, the average achievement rate is also $85.53 \%$, but more achievements in the first seven POs fluctuate. Finally, the Summer 19-20, which was entirely online, the achievement rates were not stable. The first five POs that were more knowledge-based and lower cognitive domains seem to have more achievement rate. Whereas the lack of lab experience and skill training, the upper cognitive domain, psychomotor and affective domain POs suffer. As a result, the average achievement rate reduces to $80.56 \%$.

Therefore, from the comparative analysis, the first five POs, mainly the cognitive domain teaching learning and assessment, should online or at least a mixture of both face-to-face and elearning. This pedagogy will increase the achievement rates of the students and help to implement the OBE more effectively. Whereas for the last seven POs, face-to-face education is necessary as more skill-based education is required. 


\section{CONCLUSION}

In conclusion, the above presented data and the comparative analysis of Face-to-face, Online, and partial Online gives a clear demonstration that the cognitive domain course outcomes aligned with PO-a to PO-e are suitable for online teachinglearning. It also provides more effective teaching and assessment methods using an e-learning platform. Simultaneously, the skill-based course outcomes aligned with PO-f to PO-k require physical interaction with students for the teaching-learning process. The last PO - 1, which focuses on Lifelong learning, can also be attained by an e-learning platform.

In addition to that, Outcome Based Education is more focused on student learning and outcome-driven compared to traditional course objective-based education. Therefore, student motivation, awareness, and self-driven learning methods are more suitable for e-learning platforms. Hence it is recommended that even after a pandemic when the universities go back to normal activities, some e-learning modules should be included in the curriculum to assess the student learning outcome.

\section{ACKNOWLEDGMENT}

The author acknowledges the Department of Electrical and Electronics Engineering faculty members to access the student outcomes. The authors also recognize the OBE committee members and management to support the research.

\section{REFERENCES}

[1] Ali Asif Shawon, "Bangladesh closes all educational institutions till March 31," Published at Dhaka Tribune on 12:22 pm March 16, 2020. [Online]. Available: dhakatribune.com/bangladesh/dhaka/2020/03/16/

[2] "AIUB Goes Virtual: Classes Shift Online," Published on March 20, 2020. [Online]. Available: https://www.aiub.edu/aiub-goes-virtualclasses-shift-online

[3] International Engineering Alliance. 2014. "25 Years of the Washington Accord," 2014. [Online]. Available:

http://www.ieagreements.org/assets/Uploads/Documents/History/25Year sWashingtonAccord-A5booklet-FINAL.pdf.

[4] K.Y. Tshai, J.-H. Ho, E.H. Yap \& HK Ng, "Outcome-based Education The Assessment of Programme Educational Objectives for an Engineering Undergraduate Degree," Engineering Education, 9:1, 74-85, 2014. DOI: 10.11120/ened.2014.00020

[5] BAETE. 2017. "Accreditation Manual for Undergraduate Engineering Programmes." INSTITUTION OF ENGINEERS, BANGLADESH. [Online]. Available:

http://www.baetebangladesh.org/BAETE_Manual_05.04.2017.pdf.

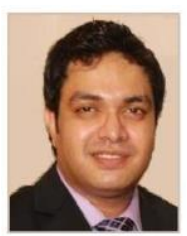

M. Tanseer Ali has completed his B.Sc. in Electrical and Telecom Engineering from North South University, Dhaka in 2007. Then he perused higher studies and received M.Sc. in Communication Engineering with Distinction from Robert Gordon University, Aberdeen, UK, in 2008. He received a full scholarship from the University of
Greenwich, London, UK, for the Ph.D. degree. He completed his doctorate in 2013. Currently, he is working as a Senior Assistant Professor at the Department of EEE, Faculty of Engineering, AIUB, Dhaka. His research interest is in Microwave Circuit and Systems, Antenna Design, Nanoelectronics, CMOS Circuits, VLSI, Analog and Mixed Circuit and IC Design, Quantum Properties of materials, Engineering Education, and Pedagogy.

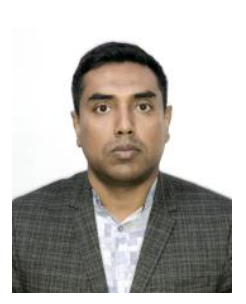

Md. Abdur Rahman is an experienced Researcher with a demonstrated history of working in the higher education industry. $\mathrm{He}$ has extensive knowledge of Radio Frequency (RF), Wireless communication, Biomedical Imaging, Machine Learning, and Antenna propagation. Profound research professional with Doctor of Philosophy (Ph.D.) from Tokyo Institute of Technology University in 2013 focused on Software Defined Radio (SDR) and has experience as a Postdoctoral Researcher in Federation University Australia from 2014, focused on Application of modern signal processing techniques in gene expressions to form gene regulatory network (GRN). His research interest is focused on RF/Microwave Circuits and Systems, Digital Signal Processing, Biomedical Image processing, Nano-electronics, Machine Learning, Wireless communication, Antenna propagation. Currently, he is working as an Associate Dean in the Faculty of Engineering at American International University-Bangladesh (AIUB) and a professor in EEE, AIUB.

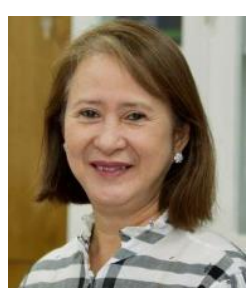

Carmen Z. Lamagna is the current vicechancellor of American International University Bangladesh (AIUB), appointed by the president of Bangladesh. She served as the president of Association of Universities of Asia and the Pacific (AUAP) and treasurer of International Association of University Presidents (IAUP). Lamagna earned her bachelor's degree in chemical engineering in 1978 from Adamson University, Manila. She received three master's degrees from Philippine Normal University (1990), Rizal Technological University (1994), and University of the East (1995). In 2003, she obtained her Ph.D. in business administration from California Coast University. Lamagna was a faculty member of Perpetual Help University (1978-1979) and AMA Computer College (1982-1994). She served as the project director of AIUB during 1994-1996 and as an assistant vice president of business development in AMA Computer College in 1996. She was appointed as the vicechancellor of AIUB in 1997. She became the first female vicechancellor of a university in Bangladesh. 